\title{
SEOM clinical guidelines on cardiovascular toxicity (2018)
}

\author{
J. A. Virizuela' (1) A. M. García ${ }^{2} \cdot$ R. de las Peñas ${ }^{3} \cdot$ A. Santaballa ${ }^{4} \cdot$ R. Andrés ${ }^{5} \cdot$ C. Beato $^{6} \cdot$ S. de la Cruz $^{7} \cdot$ J. Gavilá $^{8}$. \\ S. González-Santiago ${ }^{9} \cdot$ T. L. Fernández ${ }^{10}$
}

Received: 12 December 2018 / Accepted: 12 December 2018 / Published online: 9 January 2019

(c) The Author(s) 2019

\begin{abstract}
One of the most common side effects of cancer treatment is cardiovascular disease, which substantially impacts long-term survivor's prognosis. Cardiotoxicity can be related with either a direct side effect of antitumor therapies or an accelerated development of cardiovascular diseases in the presence of preexisting risk factors. Even though it is widely recognized as an alarming clinical problem, scientific evidence is scarce in the management of these complications in cancer patients. Consequently, current recommendations are based on expert consensus. This Guideline represents SEOM's ongoing commitment to progressing and improving supportive care for cancer patients.
\end{abstract}

Keywords Chemotherapy $\cdot$ Cardiotoxicity $\cdot$ Early detection $\cdot$ Risk assessment $\cdot$ Cancer

J. A. Virizuela

javirizuelae@seom.org

A. M. García

anamartin.amg@gmail.com

R. de las Peñas

ramon.delaspenas1956@gmail.com

A. Santaballa

santaballa_ana@gva.es

R. Andrés

andresraquel@hotmail.com

C. Beato

cbeatoz@hotmail.com

S. de la Cruz

sdelacrs@navarra.es

J. Gavilá

jgavila@fivo.org

S. González-Santiago

santigsanti@gmail.com

T. L. Fernández

tlfernandez8@gmail.com

1 Servicio de Oncología Médica, Complejo Hospitalario

Regional Virgen Macarena, Av. Doctor Fedriani, 3,

41009 Seville, Spain
2 Servicio de Cardiología, Complejo Asistencial Universitario de Salamanca (CAUSA), Instituto de Investigación Biomédica de Salamanca (IBSAL), Ciber CV, Salamanca, Spain

3 Servicio de Oncología Médica, Hospital Provincial de Castellón, Castellón de la Plana, Spain

4 Servicio de Oncología Médica, Hospital Universitari I Politècnic la Fe, Valencia, Spain

5 Servicio de Oncología Médica, Hospital Clínico Universitario Lozano Blesa, Zaragoza, Spain

6 Servicio de Oncología Médica, Complejo Hospitalario Regional Virgen Macarena, Sevilla, Spain

7 Servicio de Oncología Médica, Complejo Hospitalario de Navarra, Pamplona, Spain

8 Servicio de Oncología Médica, Fundación Instituto Valenciano de Oncología (IVO), Valencia, Spain

9 Servicio de Oncología Médica, Complejo Hospitalario Universitario de Cáceres, Cáceres, Spain

10 Servicio de Cardiología, Hospital Universitario La Paz, IdiPAZ, CiberCV, Madrid, Spain 


\section{Introduction}

Cardiovascular (CV) diseases compete with second malignancies as the leading cause of mortality in cancer survivors. Antineoplastic treatments nearly triple the risk for CV events over the medium and long term [1]. Clinical management of these toxicities with the aid of multidisciplinary protocols for prevention, diagnosis, and treatment, decreases unnecessary antitumor treatment discontinuation and optimizes global patient's outcomes [2].

Table 1 Cardiotoxicity risk factors

\begin{tabular}{|c|c|}
\hline & Cardiotoxicity Risk Factors \\
\hline Demographic cha & ristics \\
\hline $\begin{array}{l}- \text { Female } \\
\text { - Age }<15 \text { or }>65 \text { y }\end{array}$ & \\
\hline Previous cancer $\mathbf{t}$ & lents \\
\hline $\begin{array}{l}\text { - High-dose anthra } \\
\text { - High-dose (>30 G } \\
\text { - Lower-dose anthr } \\
\text { (sequential therap }\end{array}$ & $\begin{array}{l}\text { e (e.g., }>250 \mathrm{mg} / \mathrm{m}^{2} \text { doxorubicin or equivalent) } \\
\text { racic radiotherapy } \\
\text { ine in combination with thoracic radiotherapy or trastuzumab }\end{array}$ \\
\hline Current anticance & rapies \\
\hline - Cardiotoxicity risk & ends on the therapeutic scheme. See Table 2. \\
\hline $\begin{array}{l}\text { Multiple CV risk } \\
\text { factors }(\geq 2)\end{array}$ & Treatment Targets for CV Risk Factors control \\
\hline Hypertension & $\begin{array}{l}<130 / 80 \mathrm{~mm} \mathrm{Hg} \text { (start anti-hypertensive therapy if } \mathrm{BP}>140 / 90 \\
\mathrm{mmHg} \text { or BP }>160 / 90 \mathrm{mmHg} \text { if }>80 \text { yo) }\end{array}$ \\
\hline Diabetes & $\mathrm{Hb}$ A1c $<7.5 \%$ \\
\hline Dyslipidemia & $\begin{array}{l}\text { Secondary prevention or very high CV risk*: LDL-Cholesterol } \\
<70 \mathrm{mg} / \mathrm{dl} \\
\text { Primary prevention if high CV risk*: LDL-Cholesterol <100mg/dl } \\
\text { Primary prevention if low-moderate CV risk*: LDL-Cholesterol } \\
<115 \mathrm{mg} / \mathrm{dl}\end{array}$ \\
\hline Smoking & No \\
\hline Obesity & $<25 \mathrm{~kg} / \mathrm{m}^{2}$ \\
\hline Sedentary lifestyle & $>2.5$ hours/ week of moderate to intense physical activity \\
\hline $\begin{array}{l}\text { Non-cardiac cond } \\
\text { electrolyte abnorm }\end{array}$ & $\begin{array}{l}\text { that may increase cardiotoxicity risk: Thyroid dysfunction, } \\
\text {, chronic kidney disease }\end{array}$ \\
\hline $\begin{array}{l}\text { Prior heart diseas } \\
\text { - Borderline low lef } \\
\text { - History of heart fa } \\
\text { arrhythmias (atrial } \\
\text { tachycardia), mode }\end{array}$ & $\begin{array}{l}\text { ricular ejection fraction ( } 50 \% \text { to } 55 \%) \\
\text { cardiomyopathy, myocardial infarction, clinically relevant cardiac } \\
\text { tion, prolonged QT, supraventricular tachycardia, ventricular } \\
\text { or severe valvular heart disease }\end{array}$ \\
\hline
\end{tabular}

$B P$ blood pressure, $C V$ Cardiovascuar

*https://heartscore.escardio.org/2012/calc.aspx?model=europelow 


\section{Cardiotoxicity risk stratification}

Although we do not have evidence-based prospective cardiotoxicity scores to stratify the risk for cancer treatmentrelated $\mathrm{CV}$ complications, data from clinical trials and real-life registries enable us to recognize populations at increased risk. Table 1 summarizes the most common variables increasing cardiotoxicity risk [3-5].

\section{Preventive strategies}

The prevention of cardiotoxicity begins before cancer therapy, with the cardiologist and the oncologist working together to stratify baseline risk and to decide the best therapeutic approach for each patient. Additionally routine periodic assessment of cardiac function is recommended during and at the end of treatment according to local multidisciplinary protocols [6]. As general rules:

At baseline, minimizing the use of potentially cardiotoxic therapies, if established alternatives would not compromise outcome, is critical to decrease CV events [7, 8]. Optimization of $\mathrm{CV}$ risk factors and previous $\mathrm{CV}$ conditions is mandatory, as well as a structured advice regarding a healthy lifestyle (diet, smoking and exercise). CV risk stratification with the EAPC'S HeartScore (https://heartscore.escardio.org/2012/ calc.aspx?model=europelow) helps to define specific therapeutic goals for CV risk factors' control (Table 1) [3, 4, 9]. Baseline echocardiography, in patients at risk for heart failure (HF), helps to optimize CV therapy and to define individuals requiring a close supervision during therapy [10]. Universal primary prevention based on standard HF drugs is controversial and only small studies have demonstrated clinical benefit in high-risk populations [11-14].

During and after therapy, continuing CV risk control and active CV monitoring are critical issues. Cardiac biomarkers (e.g., cardiac troponins) and echocardiography in patients at risk for $\mathrm{HF}$ allow for early detection and treatment of subclinical myocardial damage, thereby preventing further events [15].

\section{Monitoring and diagnosis of cardiotoxicity}

We define cardiotoxicity as any cancer treatment-related CV event. Diagnostic criteria are similar to those used for general population, with the exception of cardiac dysfunction due to antitumor medication that is defined as a decrease in left ventricular ejection fraction (LVEF) $>10 \%$ from baseline to a final LVEF below the lower limit of normal $(<53 \%)[4,16]$. Table 2 summarizes the most common CV side effects of anticancer therapies [17]. Baseline evaluation before potentially cardiotoxic treatments should include the following:
- History and physical examination: recording the presence of cardiovascular risk factors (CVRF), preexisitng structural heart disease (Table 1), and prior cardiotoxic treatments [3, 4].

- Electrocardiogram (ECG): if abnormal a cardio-oncologyconsultation is recommended [18].

- Cardiac biomarkers: cardiac troponins are considered an alternative to serial echocardiograms in the ESMO Guidelines for cancer treatment monitoring in patients under anthracyclines \pm trastuzumab or tyrosine kinase inhibitors [19-21]. Baseline values are needed to evaluate significant changes during follow-up.

- Imaging techniques: echocardiography is deemed the technique of choice when undertaking a global comprehensive assessment of cardiac structure and function at baseline and during the cancer process. In patients with poor image quality, cardiac magnetic resonance is the best option to avoid the radiation associated with nuclear medicine techniques $[3,4,16]$. Monitoring protocols during treatment should be adapted to both the availability of local resources and the professionals' expertise [3, 4] to avoid unjustified delays in cancer treatment. Figure 1 summarizes the monitoring process in patients at risk for developing heart failure.

\section{Cancer treatment-related CV complications}

\section{Myocardial dysfunction and heart failure}

Myocardial dysfunction and heart failure (HF) are nowadays the most common recognized cancer therapy-related $\mathrm{CV}$ complications and much of the focus has been in the early detection and prevention of HF.

\section{Anthracyclines}

Doxorubicin is associated with a $5 \%$ incidence of congestive HF with a cumulative lifetime dose of $400 \mathrm{mg} / \mathrm{m}^{2}$. Cardiotoxicity risk increases with higher doses $(48 \%$ at $700 \mathrm{mg} / \mathrm{m}^{2}$ ) [22]. However, recent studies have demonstrated that there is truly no safe dose of anthracyclines and $\mathrm{HF}$ rates can be up to $10 \%$ with standard doses in patients $>65$ years or with preexisting $\mathrm{CV}$ risk factors or cardiac diseases [22].

Acute toxicity is rare (1\%) and usually manifests as supraventricular arrhythmias, transient LV dysfunction, or electrocardiographic changes (QT prolongation). For a long time it has been considered that subacute anthracycline damage was irreversible. However, active monitoring allows us for early diagnosis of HF and early treatment, ideally in asymptomatic patients, may change the natural history of 
Table 2 Cardiovascular toxicity due to antineoplastic drugs

\begin{tabular}{|c|c|}
\hline Cardiovascular toxicity & Associated drugs \\
\hline Heart failure & $\begin{array}{l}\text { Doxorubicin, daunorubicin, idarubicin, epirubicin, mitoxantrone } \\
\text { Cyclophosphamide, ifosfamide } \\
\text { Docetaxel } \\
\text { Trastuzumab, bevacizumab } \\
\text { Sunitinib, pazopanib, sorafenib, imatinib, dasatinib, lapatinib, nilotinib } \\
\text { Carfilzomib, Bortezomib }\end{array}$ \\
\hline Myopericarditis & $\begin{array}{l}\text { Cyclophosphamide } \\
\text { 5-fluorouracil, cytarabine } \\
\text { Trastuzumab, rituximab } \\
\text { Interleukin-2 } \\
\text { Immune-checkpoint inhibitors }\end{array}$ \\
\hline Ischemic cardiomyopathy & $\begin{array}{l}\text { 5-fluorouracil, capecitabine } \\
\text { Cisplatin } \\
\text { Paclitaxel, docetaxel } \\
\text { Etoposide } \\
\text { Bebacizumab } \\
\text { Sorafenib, sunitinib } \\
\text { Bleomycin }\end{array}$ \\
\hline Atrial fibrillation & $\begin{array}{l}\text { Cisplatin } \\
\text { Cyclophosphamide, ifosfamide, melphalan } \\
\text { Doxorubicin } \\
\text { Capecitabine, 5-FU } \\
\text { Gemcitabine } \\
\text { Etoposide } \\
\text { Paclitaxel } \\
\text { Rituximab } \\
\text { Sorafenib, sunitinib, ibrutinib } \\
\text { Bortezomib } \\
\text { Interleukin-2, interferon }\end{array}$ \\
\hline Bradyarrhythmias & $\begin{array}{l}\text { Cisplatin } \\
\text { Cyclophosphamide, ifosfamide } \\
\text { Doxorubicin, epirubicin, mitoxantrone } \\
\text { Capecitanina, 5-FU } \\
\text { Gemcitabine } \\
\text { Paclitaxel } \\
\text { Thalidomide } \\
\text { Imatinib, bortezomib } \\
\text { Rituximab } \\
\text { Arsenic trioxide, interleukin-2 }\end{array}$ \\
\hline Accelerated atherosclerosis & $\begin{array}{l}\text { Bevacizumab, nilotinib, ponatinib } \\
\text { Carfilzomib, bortezomib }\end{array}$ \\
\hline Pericardial effusion & $\begin{array}{l}\text { Cyclophosphamide } \\
\text { Immune-checkpoint inhibitors }{ }^{1}\end{array}$ \\
\hline Venous thromboembolic disease & $\begin{array}{l}\text { 5-fluorouracil } \\
\text { Cisplatin } \\
\text { Nilotinib, ponatinib, erlotinib } \\
\text { Bevacizumab } \\
\text { Vorinostat } \\
\text { L-Asparaginase } \\
\text { Immune-checkpoint inhibitors }\end{array}$ \\
\hline Arterial thromboembolic disease & $\begin{array}{l}\text { Cisplatin, carboplatin } \\
\text { Gemcitabine } \\
\text { Bleomycin } \\
\text { Vincristine } \\
\text { Nilotinib, ponatinib } \\
\text { Bevacizumab } \\
\text { Interferon alfa-2 } \\
\text { Immune-checkpoint inhibitors }\end{array}$ \\
\hline Arterial hypertension & $\begin{array}{l}\text { Bevacizumab } \\
\text { Sorafenib, sunitinib, axitinib, vandetanib, regorafenib }\end{array}$ \\
\hline
\end{tabular}


Table 2 (continued)

\begin{tabular}{ll}
\hline Cardiovascular toxicity & Associated drugs \\
\hline Pulmonary hypertension & Dasatinib \\
& Cyclophosphamide \\
Prolonged QT interval & Doxorubicin \\
& Depsipeptide, vorinostat \\
& Axitinib, cabozantinib, crizotinib, dasatinib, lapatinib, nilotinib, \\
& sorafenib, sunitinib, vandetanib, vemurafenib, ribociclib \\
& Arsenic trioxide \\
\hline
\end{tabular}

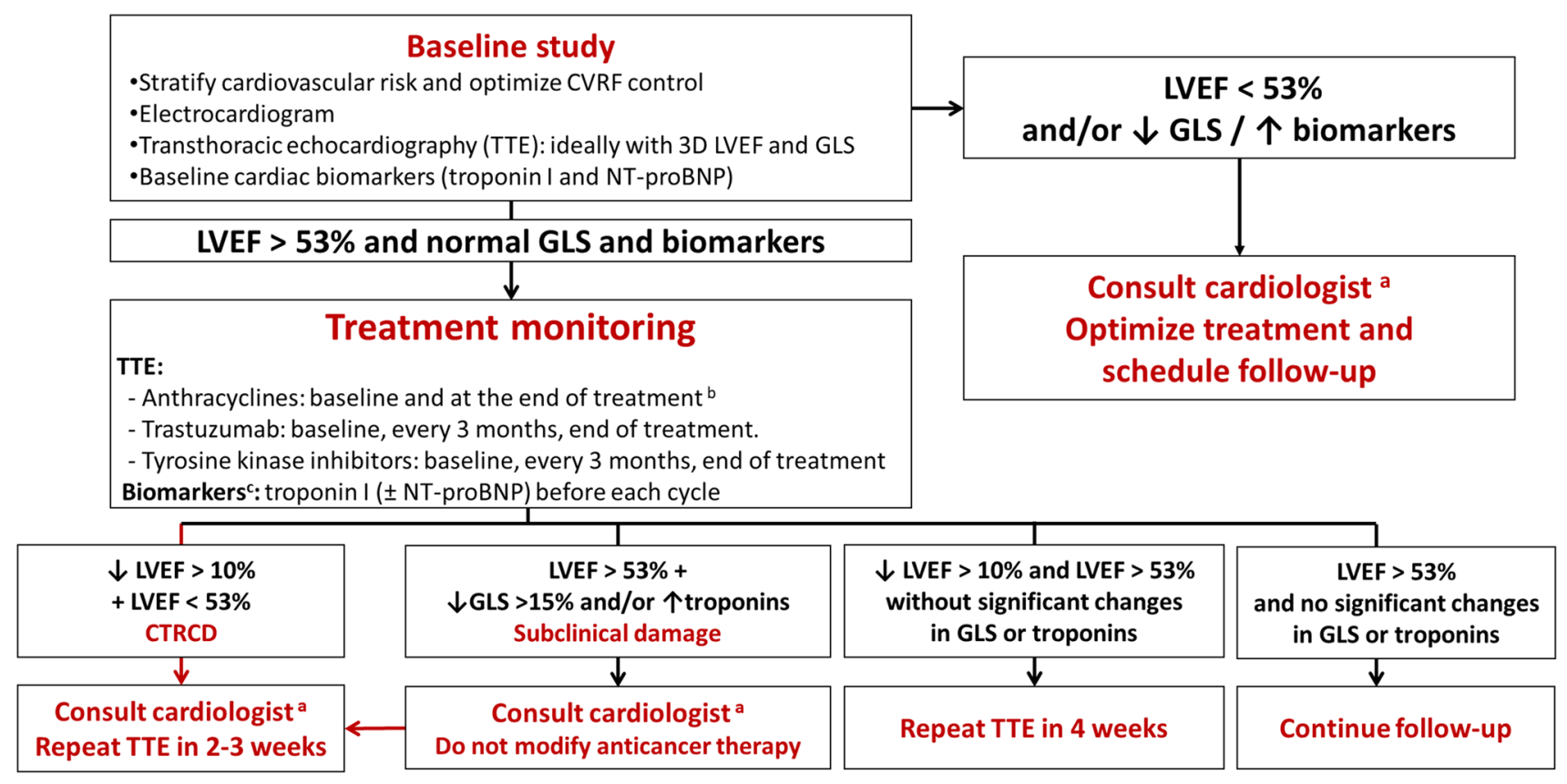

Fig. 1 Monitoring algorithm in patients receiving drugs at risk of heart failure. Modified from [4]. 3D 3-dimensional, CTRCD cancer therapeutics-related cardiac dysfunction, $C V R F s$ cardiovascular risk factors, $G L S$ global longitudinal strain, $L V E F$ left ventricular ejection fraction, NT-proBNP $\mathrm{N}$-terminal pro-B type natriuretic peptide, TTE transthoracic echocardiography. Ideally, a specialist cardio-oncohematology clinic. b Reevaluation of LVEF is recommended before treatment completion if the cumulative dose exceeds $240 \mathrm{mg} / \mathrm{m}^{2}$. In these patients, the LVEF should be regularly monitored until the end of treatment. c In patients with low cardiovascular risk and without history of cardiotoxic treatment, determination of troponin levels before each cycle reduces the number of echocardiograms required and limits their use to symptomatic patients or those with troponin elevation

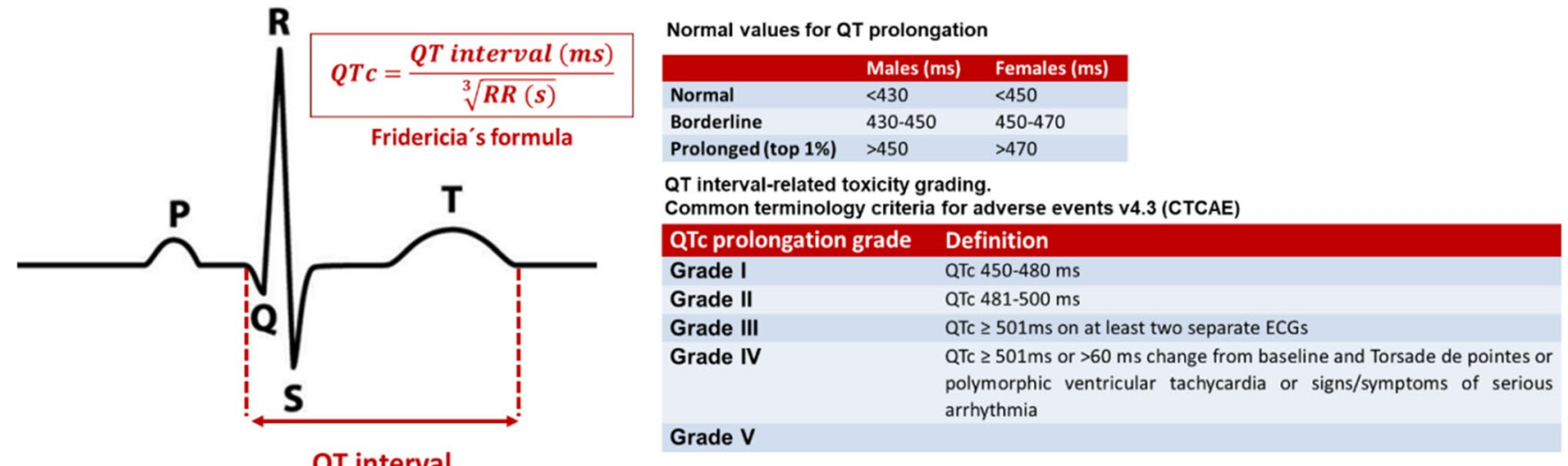

Fig. 2 Corrected QT interval calculation using the Fridericia's formula [18] and QT interval-related toxicity grading. Fridericia's formula $(\mathrm{QTc}=\mathrm{QT}$ interval $/ \sqrt[3]{R R})$ is the preferred correction formula for oncology population. (QTc corrected QT interval, $m s$ milliseconds, $s$ seconds) 


\section{Atrial fibrillation and cancer}

\section{Evaluate risk}

- Bleeding: HAS-BLED score and individual cancer-related risk (tumor site, stage and histology, intracranial tumor, thrombocytopenia, coagulopathy...)

- Embolic: $\mathrm{CHA}_{2} \mathrm{DS}_{2}-\mathrm{VAS}_{\mathrm{c}}$ score for non valvular atrial fibrillation or indication for anticoagulation due to valvular atrial fibrillation (mechanical cardiac prosthetic valves and moderate to severe rheumatic mitral stenosis) or venous/arterial thromboembolic disease

\begin{tabular}{|c|c|}
\hline $\begin{array}{c}\text { Low bleeding risk } \\
\text { (HAS-BLED }<3 \text { without cancer-related risk factors) }\end{array}$ & $\begin{array}{c}\text { Very high bleeding risk } \\
\text { Individualize }^{\text {a }}\end{array}$ \\
\hline
\end{tabular}

- $\mathrm{CHA}_{2} \mathrm{DS}_{2}-\mathrm{VAS}_{\mathrm{c}} \geq 1$ in men or $\geq 2$ in women

- Indication due to valvular atrial fibrillation or venous/arterial thromboembolic disease

- Anticoagulate $^{\mathrm{b}}$
- Acenocoumarol/warfarin
- DOACs
(Can be considered if $\mathrm{CrCl}$ is $>30 \mathrm{~mL} / \mathrm{min}$ and no significant
drug-drug interactions are registered)

Fig. 3 Algorithm for antithrombotic therapy in patients with cancerrelated atrial fibrillation. Indication algorithm for anticoagulation in patients with cancer-related atrial fibrillation. Figure modified from [4]. 5-FU 5-fluorouracil, CHA2DS2-VASc congestive heart failure, hypertension, age $>75$ years (dual), diabetes mellitus, stroke (dual), vascular disease, age 65-74 years, and sex (female), $\mathrm{CrCl}$ creatinine clearance, $C Y P$ cytochrome $\mathrm{P} 450, D O A C s$ direct oral anticoagulants, $E P O$ erythropoietin, $H A S-B L E D$ hypertension, abnormal renal and liver function, stroke, history of or predisposition to bleeding, labile

anthracycline toxicity. Therefore, modern registries found $98 \%$ of cases diagnosed during the first year of treatment in asymptomatic patients $[4,20]$.

\section{Other conventional chemotherapies}

Cyclophosphamide cardiotoxicity is relatively rare (generally occurring at higher doses $>140 \mathrm{mg} / \mathrm{kg}$ ) [23]. Cisplatin and ifosfamide are uncommon causes of HF, usually due to volume overload during treatment infusion. Docetaxel also appears to increase HF risk in patients with preexisting cardiac diseases [3].

In several large-scale trials of adjuvant therapy in breast cancer, the rate of trastuzumab-related cardiac dysfunction ranged from 7 to $34 \%$, with HF class III or IV rates between 0 and 4\% [24].The risk is higher in patients with preexisting $\mathrm{CV}$ diseases or hypertension and lower in anthracycline-free regimens [3].
- $\mathrm{CHA}_{2} \mathrm{DS}_{2}-\mathrm{VAS}_{\mathrm{c}}<1$ in men or $<2$ in women

- Without other indications for anticoagulation due to cardiovascular diseases

\begin{tabular}{|l|}
\hline \multicolumn{1}{|c|}{ Do not anticoagulate } \\
Consider anticoagulation for patients with: \\
Tumors with high embolic risk (pancreatic, lung, ovarian) \\
Treatment with prothrombotics drugs (gemcitabine, 5-FU, \\
cisplatin, EPO, colony-stimulating factors, immunomodulatory \\
drugs and steroids)
\end{tabular}

international normalized ratio, age $>65$ years, and concomitant use of drugs or alcohol, $L M W H$ low-molecular-weight heparin, $P$-gp P-glycoprotein. ${ }^{a}$ For patients with very high bleeding risk and indication for anticoagulation the decision should be individualized. Considered in a multidisciplinary discussion if left atrial appendage occlusion. ${ }^{b}$ Anticoagulant selection depends on clinical status, comorbidities, and possible interactions with the patient's anticancer therapy. ${ }^{\mathrm{c}} \mathrm{Cur}-$ rently, there is limited scientific evidence on its use in patients under active anticancer therapy and atrial fibrillation

Anti-VEGF antibody (bevacizumab) induced LV dysfunction in $2 \%$ and TKIs (sunitinib, pazopanib and axitinib) in $3-15 \%$ [3].

Practical recommendations for patients with symptoms of HF or significant changes in LVEF [3, 4, 25].

1. Confirm echo data of left ventricular dysfunction (repeat echo at 2-3 weeks).

2. Evaluate symptomatic status and check NT-proBNP.

3. If LVEF is $<53 \%$ or other pathologic findings are noticed the patients must be referred to the cardio-oncology unit to consider HF therapy and a multidisciplinary discussion is needed to reevaluate cancer treatment strategy.

\section{Arterial hypertension}

New European Society of Cardiology clinical practice guidelines define arterial hypertension as a blood pressure 


\title{
Mechanism and prevention of ischemic heart disease during cancer treatment
}

\begin{tabular}{|c|c|c|c|}
\hline \multicolumn{2}{|c|}{ Sustained vascular disease ${ }^{*}$} & \multicolumn{2}{|c|}{ Transient vascular disease } \\
\hline $\begin{array}{l}\text { Accelerated } \\
\text { atherosclerosis } \\
\text { Ponatinib-Nilotinib } \\
\text { Thoracic radiotherapy }\end{array}$ & $\begin{array}{c}\text { Progressive endothelial } \\
\text { dysfunction } \\
\text { Platinum compounds } \\
\text { VEGF inhibitors }\end{array}$ & $\begin{array}{l}\text { Acute thrombosis } \\
\text { Platinum compounds } \\
\text { VEGF inhibitors }\end{array}$ & $\begin{array}{c}\text { Acute vasospasm } \\
\text { Taxanes } \\
\text { Fluoropyrimidines }\end{array}$ \\
\hline
\end{tabular}

\author{
Blood pressure $\quad<140 / 85 \mathrm{mmHg}(\mathrm{ACEl}+/-\mathrm{ARB}+/-\mathrm{BB})$ \\ LDL-cholesterol $^{* *}<70 \mathrm{mg} / \mathrm{dl}$ in very high risk patients / IHD / DM / Severe CKD \\ $<100 \mathrm{mg} / \mathrm{dl}$ in high risk patients \\ HbA1c $\quad<7 \%$ (in patients $>75$ years-old $\mathrm{HbA} 1 \mathrm{c}<7,5-8 \%$ ) \\ Physical activity Minimum of 150 minutes/week of moderate exercise \\ Diet Mediterranean healthy diet \\ Smoking NO
}

- Vasospasm suspicion: Non-invasive coronary angiography (Cardiac computed tomography) and nitrates+/amlodipine to prevent recurrences if there is no therapeutic alternative

- In ACS: Individualize revascularization strategies and minimize the duration of DAPT to reduce the risk of bleeding and thrombosis

- Long-term follow-up in patients at risk of accelerated atherosclerosis: Functional non-invasive stress test for coronary artery disease detection in asymptomatic high risk patients ${ }^{* * *}$

Fig. 4 Mechanism and prevention of ischemic heart disease during cancer treatment. *Sustained vascular disease: more permanent and progressive disease, even after discontinuation of treatment. **Cardiovascular risk calculator: http://secardiologia.es/multimedia /apps/5696-calculadora-riesgo-cardiovascular. High-risk patients: radiotherapy in patients whose target volume includes at least part of the heart +1 risk factor $(<15$ or $>65$ years-old at treatment; $>30 \mathrm{~Gy}$ or $>2$ Gy/day; treatment with other cardiotoxic agents; previous

$>140 / 90 \mathrm{mmHg}$ in the office or $>130 / 80 \mathrm{mmHg}$ during ambulatory measurements [26].

Hypertension is the most common comorbidity in cancer patients $[3,4,21]$. It is present in more than $30 \%$ of patients, due to both the high prevalence of hypertension in aged cancer populations and the effect of certain anticancer drugs. Oncological therapies cause hypertension through different mechanisms, although the most frequent are drugs that inhibit angiogenesis and interact with vascular endothelial growth factors such as VEGF inhibitors (e.g., bevacizumab), tyrosine kinase inhibitors (e.g., sunitinib), and sorafenib. It has been reported that VEGF inhibitors induce new hypertension or destabilizing previously controlled hypertension in $11-45 \%$ of patients [27].

Blood pressure should be monitored before and during cancer treatment and properly managed, following standard pharmacological and dietary recommendations for the general population $[3,4,26]$.

Blood pressure target in patients with uncomplicated hypertension is $<130 / 80 \mathrm{mmHg}$. Renin-angiotensin ischemic heart disease, or preexisting classical cardiovascular risk factors). DAPT dual antiplatelet therapy, ACS acute coronary syndromes, $C T$ computed tomography, $V E G F$ vascular endothelial grow factor, $C V R F$ cardiovascular risk factors, $A C E I$ angiotensin converting enzyme inhibitors, $A R B$ angiotensin II receptor antagonist, $B B$ beta-blockers, $I H D$ ischemic heart disease, $D M$ diabetes mellitus, $C K D$ chronic kidney disease

system blockers, betablockers and dihydropyridin calcium channel blockers are considered the drugs of choice, given their protective profile against the onset of HF. In uncontrolled patients double or triple therapy is recommended as well as the addition of antialdosteronic agents. Thiazides should be used with caution because of the risk of hypokalemia and QTc prolongation. The use of negative inotropics drugs (diltiazem and verapamil) is not advised as they block the CYP3A4 isoenzyme, which is involved in the metabolic pathway of some tyrosin kinase inhibiotrs like sorafenib [26].

\section{Cardiac arrhythmias}

There are increasing data that a growing number of anticancer drugs could cause pro-arrhythmic cardiotoxicity [18, 28] (Table 2). Cancer therapy might produce electrophysiological changes, such as QT prolongation, as well as a wide range of cardiac arrhythmias, including bradyarrhythmias and supraventricular and ventricular tachycardias [3,4]. 
Fig. 5 Management algorithm for suspected autoimmune myocarditis

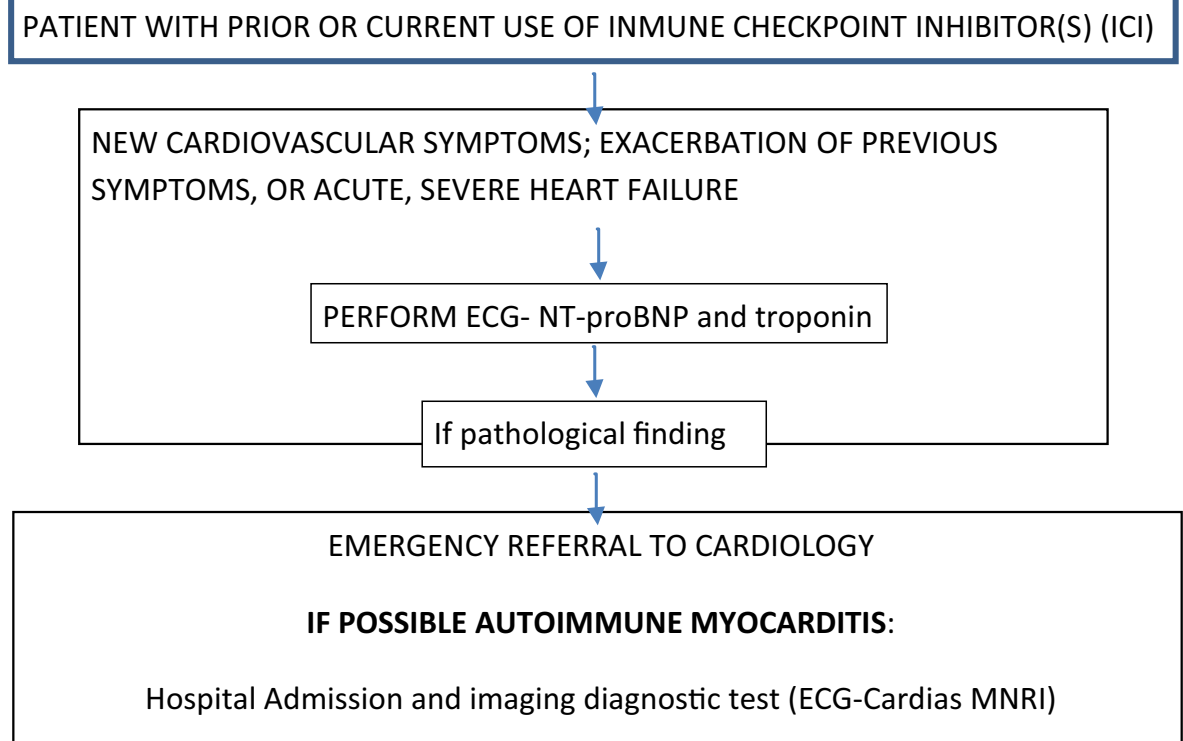

Arrhythmias might be only slightly perceptible, yet cause severe symptoms or even sudden cardiac death. Oncological diseases themselves predispose to the development of arrhythmias, which may be present at baseline in 16-36\% of patients [3, 4, 28]. Management of arrhythmias should be based on cardiac- and cancer-related life expectancy, quality of life, and complication risks [3, 4, 28].

Initial assessment of patients who receive potential QT-prolonging drugs should include a baseline electrocardiogram and regular monitoring of the QT interval during therapy [3, 4, 28, 29] (Fig. 2). Withdrawal of these drugs or administration under hospital monitoring should be considered, if corrected QT interval is $>500 \mathrm{~ms}$ or increased by more than $60 \mathrm{~ms}$ from baseline [3, 4].

Atrial fibrillation (AF) is the most common sustained arrhythmia in cancer patients. Treating AF in patients receiving active anticancer therapy is a challenge owing to several factors, including the need for frequent procedures, malignancy-related risk factors for bleeding and/or thrombosis, drug-drug interactions, and the choice of anticoagulant treatment. Nowadays $\mathrm{CHA}_{2} \mathrm{DS}_{2} \mathrm{VASc}$ score is recommended to guide embolic risk stratification (Fig. 3) [4, 30-32]. Currently, there is limited scientific evidence on the use of direct oral anticoagulants in patients under active anticancer therapy; however, they can be considered as an alternative, in stable patients, if no significant drug-drug interaction was registered [32].

\section{Ischemic cardiomyopathy}

Despite the fact that cancer may induce ischemia by means of different mechanisms (Fig. 4), the most common ones are the sequelae from antitumor drugs and radiotherapy [3, 4, 33, 34].

Coronary heart disease (CHD) can debut as vasospasm, endothelial injury, or acute arterial thrombosis. Vasospasm has been reported during the administration of fluoropyrimidines or in the following days in up to $10 \%$ of the patients. Cisplatin induces endothelial dysfunction and arterial thrombosis, whereas VEGF pathway signaling inhibitors, such as bevacizumab, sunitinib, pazopanib, and sorafenib pose an increased risk of coronary thrombosis [36]. Radiotherapy entails a higher incidence of ischemic heart disease by means of endothelial injury, plaque rupture, and thrombosis [33, 37].

In individuals with pre-existing coronary disease who require treatment with 5-fluorouracil, etoposide, bleomycin, vinblastine, bevacizumab, sorafenib, and taxanes, it is mandatory that $\mathrm{CV}$ risk factors be controlled and development of symptoms suggestive of angina be meticulously assessed. In patients with coronary vasospasm, and normal or nonsevere coronary artery disease, nitrates or calcium antagonists' treatment minimizes vasospasm recurrence and avoids treatment interruptions. Triggers such as anemia should be minimized [3, 4].

\section{Other complications}

Both prognosis and management of neoplastic pleural effusion depends on the underlying neoplasia. Pleural effusion has been reported during treatment with targeted drugs, such as imatinib. Therapeutic approach comprises diuretic's administration; however refractory dose reduction treatment discontinuation may be necessary [38]. 
Table 3 Final recommendations

Recommendations

$\begin{array}{ll}\begin{array}{l}\text { Strength of } \\ \text { recommenda- } \\ \text { tion }\end{array} & \begin{array}{l}\text { Quality } \\ \text { of evi- } \\ \text { dence }\end{array}\end{array}$

1. Cardiotoxicity risk stratification

Patients with cancer who need any potentially cardiotoxic drug should be screened for their cardiotoxicity risk $\quad$ A

Patients with previous cardiovascular disease, prior cardiotoxic treatments, and uncontrolled cardiovascular risk fac- A tors should be considered at high risk for cardiotoxicity

Patients at high risk for cardiotoxicity should be referred for cardiovascular evaluation (ideally cardio-oncology A evaluation) before antineoplastic treatment

2. Preventive strategies for cardiotoxicity in patients at risk

Minimize the use of potentially cardiotoxic therapies

All cancer patients should receive recommendations for healthy lifestyle and physical exercise

Optimize cardiovascular risk factors and previous cardiovascular diseases treatment before, during, and after oncological therapy

3. Cardiotoxicity diagnosis

Echocardiography is the imaging technique of choice for the diagnosis and treatment of cancer related cardiovascu- A lar complications

High-risk patients should undergo more intensive follow-up, referring them, for specific Cardio-Oncology consulta- A tion

4. Heart failure monitoring and management

LV function monitoring should be performed using the same imaging technique during follow-up (2D echo, 3D echo or strain). The choice should be based on center's availability and clinician's expertise

Cardiac biomarkers helps heart failure monitoring

Patients with a LVEF under normal values (53\%) should be referred for cardio-oncology evaluation and treatment

Cancer treatment interruptions must be based on multidisciplinary team discussion after confirming the presence of A symptomatic moderate to severe LV dysfunction

5. Cardiac arrhythmia monitoring and management

Patients with cancer at risk for cardiac arrhythmias should undergo close monitoring and ECG screening during the A first weeks of therapy

Anticoagulation in patients with atrial fibrillation should be guided by CHA2Ds2-VASc and HASBLED scores

6T interval monitoring and management

Assessment of patients treated with potential QT-prolonging drugs should include a baseline electrocardiogram and regular monitoring of the cQT interval (Fridericia's correction formula)

If corrected QT interval $>500 \mathrm{~ms}$ or increases $>60 \mathrm{~ms}$ from baseline, antitumoral drugs must be withdrawn or administrated with hospital monitoring. Any modifiable risk factors (electrolyte abnormalities, use of other QTprolonging drugs, etc.) must be arranged

7. Ischemic heart disease monitoring and management

Optimal CVRF control is critical to minimize ischemic events during and after cancer treatment

8. Pulmonary hypertension monitoring and management

These patients require multidisciplinary evaluation to determine the best treatment strategy

9. Pericardial disease monitoring and management

These patients require multidisciplinary evaluation to determine the best treatment strategy

10. Monitoring of long-term survivors

Cardiovascular screening reduces the incidence of heart failure; however, there is no consensus regarding the optimal screening test or frequency of testing

During follow-up of long-term cancer survivors, lifestyle modifications to prevent cardiovascular risk factors and instruct patients to report early signs and symtoms

Patients who need treatment should be referred to Cardio-Oncology

A

D

D

B

B

B
III

III

III

II

I

III

III

III . 
Pulmonary hypertension (PHT) is an uncommon, albeit serious CV side effect that appears after exposure to certain antineoplastic medications (TKIs, mainly dasatinib). Diagnosis is based on clinical evaluation, echocardiogram, and biomarkers (NT-proBNP). These patients require multidisciplinary evaluation to determine the best treatment strategy moving forward [3, 4, 39].

Radio-induced peripheral artery disease (PAD) mainly affects arteries and capillaries. Prevention depends on a strict $\mathrm{CV}$ risk factor control and treatment recommendations are similar other high-risk populations [40].

Immune checkpoint inhibitors (ICI) are a new category of drugs that have had a great impact on the course of several advanced solid tumors. However, their use is related with immune system-mediated toxicities, including autoimmune myocarditis (AIM). Although cardiotoxic effects are uncommon, they are often associated with a high acute mortality risk. AIM prevalence increases under combination therapy and occurs more frequently during the first weeks of therapy [41]. It can manifest either as de novo $\mathrm{HF}$ or as an exacerbation of an already known HF. When AMI is suspected a prompt cardio-oncology consultation is required High-dose steroids are recommended in critical patients although there is currently little experience [42, 43]. Figure 5 summarizes clinical approach in suspected cases.

\section{Follow-up and treatment in long-term survivors}

Cardiovascular disease and second cancers are the most common cause of mortality in cancer survivors [44]. Longterm survivors that have been treated with cardiotoxic treatments or radiotherapy should be informed of their increased risk for cardiovascular diseases (CVDs). Cardiovascular screening reduces the incidence of heart failure by $18 \%$ [45], but there is a lack of agreement about the optimal test for screening and frequency of testing. We propose the algorithm recommended by Carver et al. and the Spanish Working Group in Cardio-Oncology [4, 46].

During follow-up, education in long-term cancer survivors should be based on lifestyle modifications, to prevent and treat $\mathrm{CV}$ risk factors, and instructions to report early $\mathrm{CV}$ signs and symptoms (Table 1) [3, 4].

Patients who need treatment should be referred to the consultant cardiologist or to the cardio-oncology clinic. Early treatment with ACEIs, ARA-II, and/or BB improves HF prognosis [47].

\section{Special situations}

In patients with high risk for radiotherapy-induced cardiotoxicity, ECO every 5 years is recommended $[4,33]$.
Cardiac dysfunction may first become apparent during pregnancy. Women who want to become pregnant should be carefully evaluated before, during, and after pregnancy [4].

Patients with previous neck irradiation have an increased risk of stroke. Ultrasound scanning of carotid arteries to rule out the presence of subclinical atherosclerosis is recommended [3,7].

Final recommendations, strength of recommendation and quality of evidence (Table 3).

\section{Compliance with ethical standards}

Conflict of interest JAV has nothing to disclose. AMG has nothing to disclose. RDP has nothing to disclose. AS reports speaker honoraria from Roche, Pfizer, Astra Zeneca, Novartis, MSD and Pierre Fabre and Advisory Board from Roche, Tesaro, Clovis, Astra Zeneca and Novartis, outside the submitted work has nothing to disclose. RA has nothing to disclose. CB reports grants from LEO Pharma, Roche, MSD, ROVI, Sanofi, BMS and Mylan. Has received speaker honoraria from Esteve and Kyowa Kirin and Advisory boards from Kyowa kirin, Omakase and Roche, outside the submitted work. SC has nothing to disclose. JG reports speaker honoraria from Roche, Pfizer and Novartis, and Advisory board from Roche and Novartis, outside the submitted work. SG reports advisory boards from AstraZeneca, Celgene, Roche y Novartis. TL reports honoraria for teaching from Janssen-Cilag, Teva, Gilead, Daiichi, Novartis and Pfizer, outside the submitted work.

Ethical standards The current study has been performed in accordance with the ethical standards laid down in the 1964 Declaration of Helsinki and its later amendments.

Informed consent For this type of study formal consent is not required.

OpenAccess This article is distributed under the terms of the Creative Commons Attribution 4.0 International License (http://creativeco mmons.org/licenses/by/4.0/), which permits unrestricted use, distribution, and reproduction in any medium, provided you give appropriate credit to the original author(s) and the source, provide a link to the Creative Commons license, and indicate if changes were made.

\section{References}

1. Hooning MJ, Botma A, Aleman BM, Baaijens MH, Bartelink $\mathrm{H}$, Klijn JG, et al. Long-term risk for cardiovascular disease in 10-year survivors of breast cancer. J Natl Cancer Inst. 2007;99:365-75.

2. Ewer MS, Ewer SM. Cardiotoxicity of anticancer treatments. Nat Rev Cardiol. 2015;12(9):547-58.

3. Zamorano JL, Lancellotti P, Rodríguez Muñoz D, Aboyans V, Asteggiano R, Galderisi M, et al. 2016 ESC Position Paper on cancer treatments and cardiovascular toxicity developed under the auspices of the ESC Committee for Practice Guidelines: the Task Force for Cancer Treatments and Cardiovascular Toxicity of the European Society of Cardiology (ESC). Eur Heart J. 2016;37(36):2768-801.

4. López-Fernández T, Martín-García A, Santaballa Beltrán $\mathrm{A}$, Montero LA, García Sanz R, Mazón Ramos $\mathrm{P}$, et al. Cardio-onco-hematology in clinical practice. Position 
paper and recommendations. Rev Esp Cardiol (Engl Ed). 2017;70(6):474-86.

5. Herrmann J, Lerman A, Sandhu NP, Villarraga HR, Mulvagh SL, Kohli M. Evaluation and management of patients with heart disease and cancer: cardio-oncology. Mayo Clin Proc. 2014;89:1287-306.

6. Lancellotti P, Suter TM, López-Fernández T, Galderisi M, Lyon AR, Van der Meer P, et al. Cardio-oncology services: rationale, organization, and implementation: a report from the ESC cardio-oncology council. Eur Heart J. 2018;26:45. https://doi. org/10.1093/eurhearti/ehy453.

7. Kalam K, Marwick TH. Role of cardioprotective therapy for prevention of cardiotoxicity with chemotherapy: a systematic review and meta-analysis. Eur J Cancer. 2013;49:2900-9.

8. Cardinale D, Biasillo G, Cipolla CM. Curing cancer, saving the heart: a challenge that cardioncology should not miss. Curr Cardiol Rep. 2016;18:51.

9. Piepoli M, Hoes W, Agewall S, et al. 2016 European Guidelines on cardiovascular disease prevention in clinical practice: the sixth Joint Task Force or the European Society of Cardiology and Other Societies on Cardiovascular Disease Prevention in Clinical Practice (constituted by representatives of 10 societies and by invited experts) Developed wit the special contribution of the European Association for Cardiovascular Prevention \& Rehabilitation (EACPR). Eur Heart J. 2016;37:2315-81.

10. López-Fernández T, Thavendiranathan P. Emerging cardiac image modalities for early detection of cardiotoxicity derived for anticancer therapies. Rev Esp Cardiol. 2017;70:487-95.

11. Cardinale D, Colombo A, Bacchiani G, Tedeschi I, Meroni CA, Veglia F, et al. Early detection of anthracycline cardiotoxicity and improvement with heart failure therapy. Circulation. 2015;131:1981-8.

12. Cardinale D, Colombo A, Sandri MT, Lamantia G, Colombo N, Civelli M, et al. Prevention of high-dose chemotherapy induced cardiotoxicity in high-risk patients by angiotensin converting enzyme inhibition. Circulation. 2006;114:2474-81.

13. Bosch X, Rovira M, Sitges M, Domènch A, Ortiz-Pérez JT, de Caralt TM, et al. Enalapril and carvedilol for preventing chemotherapy-induced left ventricular systolic dysfunction in patients with malignant hemopathies: the OVERCOME trial. J Am Coll Cardiol. 2013;61:2355-62.

14. Gulati G, Heck SL, Ree AH, Hoffmann P, Schulz-Menger J, Fagerland MW, et al. Prevention of cardiac dysfunction during adjuvant breast cancer therapy (PRADA): a $2 \times 2$ factorial, randomized, placebo-controlled, double-blind clinical trial of candesartan and metoprolol. Eur Heart J. 2016;37:1671-80.

15. Nolan M, Plana JC, Thavendiranathan P, Shaw L, Si L, Marwick TH. Cost effectiveness of strain-targeted cardioprotection for prevention of chemotherapy induced cardiotoxicity. Int J Cardiol. 2016;212:336-45.

16. Plana JC, Galderisi M, Barac A, Ewer MS, Ky B, ScherrerCrosbie M, et al. Expert consensus for multimodality imaging evaluation of adult patients during and after cancer therapy: a report from the American Society of Echocardiography and the European Association of Cardiovascular Imaging. Eur Heart J Cardiovasc Imaging. 2014;15:1063-93.

17. Barac A, Murtagh G, Carver JR, Chen MH, Freeman AM, Herrmann J, et al. Cardiovascular health of patients with cancer and cancer survivors: a roadmap to the next level. J Am Coll Cardiol. 2015;65:2739-46.

18. Tamargo J, Caballero R, Delpon E. Cancer chemotherapy and cardiac arrhythmias: a review. Drug Saf. 2015;38:129-52.

19. Curigliano G, Cardinale D, Suter T, Plataniotis G, de Azambuja E, Sandri MT, et al. Cardiovascular toxicity induced by chemotherapy, targeted agents and radiotherapy: ESMO clinical practice guidelines. Ann Oncol. 2012;23(Suppl 7):vii155-66.
20. Cardinale D, Sandri MT. Role of biomarkers in chemotherapyinduced cardiotoxicity. Prog Cardiovasc Dis. 2010;53:121-9.

21. Curigliano G, Cardinale D, Dent S, Criscitiello C, Aseyev OR, Lenihan D, et al. Cardiotoxicity of anticancer treatments: Epidemiology, detection, and management. CA Cancer J Clin. 2016;66:309-25.

22. Swain SM, Whaley FS, Ewer MS. Congestive heart failure in patients treated with doxorubicin: a retrospective analysis of three trials. Cance. 2003;97:2869-79.

23. Braverman AC, Antin JH, Plappert MT, Cook EF, Lee RT. Cyclophosphamide cardiotoxicity in bone marrow transplantation: a prospective evaluation of new dosing regimens. J Clin Oncol. 1991;9:1215-23.

24. Moja L, Tagliabue L, Balduzzi S, Parmelli E, Pistotti V, Guarneri V, et al. Trastuzumab containing regimens for early breast cancer. Cochrane Database Syst Rev. 2012;4:CD006243.

25. Ponikowski P, Voors A, Anker SD, Bueno H, Cleland JGF, Coats AJS, et al. 2016 ESC Guidelines for the diagnosis and treatment of acute and chronic heart failure. Eur Heart J. 2016;37:2129-200.

26. Williams B et al. 2018 ESC/ESH Guidelines for the management of arterial hypertension. The Task Force for the management of arterial hypertension of the European Society of Cardiology (ESC) and the European Society of Hypertension (ESH) Eur Heart J. 2018;00:1-98.

27. Milan A, Puglisi E, Ferrari L, Bruno G, Losano I, Veglio F. Arterial hypertension and cancer. Int J Cancer. 2014;134:2269-77.

28. Buza V, Rajagopalan B, Curtis AB. Cancer treatment-induced arrhythmias: focus on chemotherapy and targeted therapies. Circ Arrhythm Electrophysiol. 2017;10(8):e005443. https:// doi.org/10.1161/circep.117.005443.

29. Porta-Sánchez A, Gilbert C, Spears D, Amir E, Chan J, Nanthakumar K, et al. Incidence, diagnosis, and management of qt prolongation induced by cancer therapies: a systematic review. J Am Heart Assoc. 2017;6(12):e007724.

30. Farmakis D, Parissis J, Filippatos G. Insights into oncocardiology: atrial fibrillation in cancer. J Am Coll Cardiol. 2014;63:945-53.

31. Kirchhof P, Benussi S, Kotecha D, Ahlsson A, Atar D, Casadei B, et al. 2016 ESC Guidelines for the management of atrial fibrillation developed in collaboration with EACTS. Eur Heart J. 2016;37:2893-962.

32. Steffel J, Verhamme P, Potpara TS, Albaladejo P, Antz M, Desteghe L, et al. The 2018 European Heart Rhythm Association Practical Guide on the use of non-vitamin K antagonist oral anticoagulants in patients with atrial fibrillation. Eur Heart J. 2018;39:1330-93.

33. Lancellotti P, Nkomo VT, Badano LP, Bergler-Klein J, Bogaert J, Davin L, et al. Expert consensus for multi-modality imaging evaluation of cardiovascular complications of radiotherapy in adults: a report from the EACVI and the ASE. J Am Soc Echocardiogr. 2013;26:1013-32.

34. Herrmann J, Yang EH, Iliescu CA, Cilingiroglu M, Charitatis K, Hakeem A, et al. Vascular toxicities of cancer therapies: the old and the new-an evolving avenue. Circulation. 2016;133:1272-89.

35. Polk A, Vistisen K, Vaage-Nilsen M, Nielsen DL. A systematic review of the pathophysiology of 5-fluorouracil-induced cardiotoxicity. BMC Pharmacol Toxicol. 2014;15:47.

36. Qi WX, Shen Z, Tang LN, Yao Y. Risk for arterial thromboembolic events with vascular endothelial growth factor receptor tyrosine kinase inhibitors: an up-to-date meta-analysis. Crit Rev Oncol Hematol. 2014;92:71-82.

37. Desai MY, Jellis CL, Kotecha R, Johnston DR, Griffin BP. Radiation-associated cardiac disease a practical approach to diagnosis and management. J Am Coll Cardiol Img. 2018;11:1132-49. 
38. Chen MH, Kerkela R, Force T. Mechanisms of cardiac dysfunction associated with tyrosine kinase inhibitor cancer therapeutics. Circulation. 2008;118:84-95.

39. Galie N, Humbert M, Vachiery JL, Gibbs Lang I, Torbicki A, et al. ESC/ERS Guidelines for the diagnosis and treatment of pulmonary hypertension: the Joint Task Force for the Diagnosis and Treatment of Pulmonary Hypertension of the ESC and the ERS. Eur Heart J. 2015;2016(37):67-119.

40. Plana JC, Thavendiranathan P, Bucciarelli-Ducci C, Lancelloti P. Multi-modality imaging in the assessment of cardiovascular toxicity in the cancer patient. J Am Coll Cardiol Img. 2018;11:1173-86.

41. Johnson DB, Balko JM, Compton ML, Chalkias S, Gorham J, $\mathrm{Xu} \mathrm{Y}$, et al. Fulminant myocarditis with combination immune checkpoint blockade. N Engl J Med. 2016;375:1749-55.

42. Haanen JB, Carbonnel F, Robert C, Kerr KM, Peters S, Larkin $\mathrm{J}$, et al. Management of toxicities from immunotherapy: ESMO Clinical Practice Guidelines for diagnosis, treatment and followup. Ann of Oncol. 2017;29(Supplement 4):iv264-6.

43. Mahmood SS, Fradley MG, Cohen JV, Nohria A, Reynolds KL, Heinzerling LM, et al. Myocarditis in patients treated with Immune Checkpoint Inhibitors. J Am Coll Cardiol. 2018;71:1755-64.
44. Miller K, Siegel RL, Lin CC, Mariotto AB, Kramer JL, Rowland $\mathrm{JH}$, et al. Cancer treatment and survivorship statistics, 2016. CA Cancer J Clin. 2016;66:271-89.

45. Wong FL, Bhatia S, Landier W, Francisco L, Leisenring W, Hudson MM, et al. Efficacy and cost- effectiveness of the Children's Oncology Group long-term follow-Up guidelines for early detection of treatment- related cardiac compromise in childhood cancer survivors. Ann Intern Med. 2014;160:672-83.

46. Carver JR, Szalda D, Ky B. Asymptomatic cardiac toxicity in long-term cancer survivors: defining the population and recommendations for surveillance. Semin Oncol. 2013;40:229-38.

47. Wells QS, Lenihan DJ. Reversibility of left ventricular dysfunction resulting from chemotherapy: can this be expected? Prog Cardiovasc Dis. 2010;53(2):140-8. https://doi.org/10.1016/j. pcad.2010.06.005.

Publisher's Note Springer Nature remains neutral with regard to jurisdictional claims in published maps and institutional affiliations. 